\title{
Costimulation of Superantigen-Activated T Lymphocytes by Autologous Dendritic Cells Is Dependent on B $7^{1}$
}

\author{
Frank O. Nestle,* Craig Thompson, $\dagger \ddagger$ Your Shimizu, $\S$ \\ LaURENCE A. TURKA, $\dagger$ AND BRIAN J. NiCKOLOFF*,2
} *Department of Pathology, $\dagger$ Department of Imernal Medicine, $\$$ Howard Hughes Medical Institute, and
$\$$ Department of Microbiology/Immmology, University' of Michigan, Ann Arbor, Michigan $48109-0602$

\author{
Recoived January 18, 1994; accepted February 15, 1994
}

\begin{abstract}
Highly purified populations of dendritic cells (DCs) can be isolated from various tissues such as skin and blood. These sites are likely to encounter secreted toxins of bacteria such as superantigens. In viw), DCs cxpress the cell surface molecule B7, a counterreceptor for CD28 which provides costimulation to resting T cells. Highly purified preparations of DCs obtained from the epidermis and dermis of normal skin as well as blood were used to study the role of B7 in superantigen presentation to autologous $\mathrm{T}$ cells. as well as in alloantigen responses. We compared these results to these obtained with nondendritic antigen presenting cells ( $\triangle P C s$ ) such as mononuctear cells derived from the IFicoll-1lypaque interlace (P'BMCs). AlI DC populations strongly express 137, and in a purcly autologous system staphylococcal enterotoxin B (SEB)-nediated T

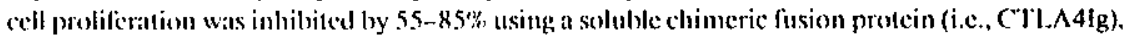
a potent inhibitor of $\mathrm{CD} 28: B 7$ interaction. In contrast, while T cells also proliferated vigorously when stimulated by SEB in the presence of autologous PBMC (which only weakly express B7), costimulation was not inhibited by CTLA4Ig. In allogeneic responses, DCs were also more poieit stimulators compared to PBMC, but both types of APC:T cell reactions were almost completely inhibited by CTLA4Ig (>90\%). For both SEB-mediated reactions and alloantigen reactions, the relative importance of LFA-1 and HLA-DR was similar between DCs and PBMCs. The data indicate that these DCs express B7, which can function in the SEB-driven response of autologous $T$ cells, as well as in allogeneic $T$ cell reactions. Overall, when comparing the relative costimulatory capabilities of different types of APCs, it appears the relatively low level of B7 expressed by PBMC functioned effectively in allogencic reactions, whereas only the higher levels of $B 7$ expressed by these DC populations functioned in SEB-mediated T cell responses. (Q) 1994 Acadernic Press, Inc.
\end{abstract}

\section{INTRODUCTION}

Although engagement of the $T$ cell receptor complex by antigen in the context of proteins encoded by the major histocompatibility complex $(\mathrm{MHC})^{3}$ essential for the

\footnotetext{
I This work was supported by National Institutes of Health Grants AI31 126 (Y.S.), IPSOAR41703 (L.A.T.), and $A R 38957,01823,40488$ (B.J.N.).

${ }^{2}$ To whom correspondence should be addressed at Department of Pathology, University of Michigan Medical School, M4232 Medical Science 1, 130। Catherine St., Ann Arbor, Mi 48109-0602. Fax: 313-9360755 .

${ }^{3}$ Abbreviations used: DC, dendritic cell; LC, Langerhans cell; SA, superantigen: SEB, staphylococcal colcotoxin 13: VWI: ven-Willduand's factor: MIC, major histocompatibility complex: $A P C s$, antigenpescenting cells; IPBMC', peripherat blood monontelear cells.
} 
initial stages of $\mathrm{T}$ cell activation, it is insufficient by itself for optimal $\mathrm{T}$ cell proliferation (1). Costimulation through additional T cell surface molecules, such as CD28, appears to be crucial for enhanced proliferation and cytokine production (2). Recently, it has been demonstrated that the $B$ cell activation antigen $B 7$ is a natural ligand for the $T$ cell costimulatory molecule CD28 (3). Engagement of CD28 with its ligand B7 is necessary and sufficient to provide costimulation for $T$ cells activated with alloantigen (4-6). However, when examined with allogeneic combinations of $T$ cells and various B cell lines, studies of the role of CD28 and B7 have produced conflicting results with respect to superantigens (SA). Using the MHC class II-positive B cell lymphoblastoid line Raji as antigen-presenting cells (APCs), mAbs against B7 blocked SA-induced activation of the IL-2 promotor as assessed by a luciferase assay (7). In contrast, using $\mathrm{T}$ cell proliferation as an index (8), blockade of $\mathrm{B} 7$ with a soluble chimeric fusion protein of CTLA-4 (i.e., CTLA4Ig), a potent inhibitor of CD28:B7 interaction (9), had no effect on the response of T cells to SA presented by the B cell line ARENDT.

Studies showing that a B7:CD28 interaction was not required for SA-induced $T$ cell proliferation were performed using allogeneic B7 positive APCs. However, under physiological conditions, bacterial SAs are presented by autologous tissue APCs. DCs are potent APCs $(10,11)$ that express B7 immunoreactivity in various organs (11-14) and are important in initiating primary immune responses. Since the functional role of B7 with respect to SA in a purely autologous system has not been defined, we examined this issue using autologous dendritic cells isolated from skin (both epidermis and dermis) and blood of normal human volunteers to present bacterial-derived SA. Our data establish the potent APC capability of DCs for SA compared to APCs derived from isolated peripheral blood mononuclear cells (PBMC) containing other nondendritic APCs, such as monocytes and B cells (15), and demonstrate that blockade of B7 inhibits the response of resting peripheral blood $\mathrm{T}$ cells to bacterial-derived SA presented by autologous DCs. Moreover, a hierarchy in the relative functional contribution of B7 emerged by comparing different APCs, such as PBMC, versus DCs. Although PBMCs only express low levels of $\mathrm{B} 7$ in allogeneic reactions this was very important as CTLA4Ig inhibited T cell proliferation by over $90 \%$, whereas in SAmediated reaction there was no inhibition by CTLA4Ig. In contrast, when all three dendritic cell populations which express high levels of B7 were used as APCs, CTLA4Ig blocked the $\mathrm{T}$ cell response in both autologous SA-mediated, as well as allogeneic $\mathrm{T}$ cell reactions. Thus, quantitative levels of $\mathrm{B} 7$ expression required for the costimulatory function of APCs vary with the nature of the primary stimulus delivered to the T cell.

\section{MATERIALS AND METHODS}

Reagents and antibodies. RPMI 1640 was supplemented with $10 \%$ FBS, $10 \mathrm{U} / \mathrm{ml}$ penicillin/streptomycin, and $50 \mu \mathrm{g} / \mathrm{ml}$ gentamicin (Gibco, Grand Island, NY). PHA was purchased from Sigma Chemical Co. (St Louis, MO) and used at $10 \mu \mathrm{g} / \mathrm{ml}$. Staphylococcal enterotoxin B (SEB) was obtained from Toxin Technology Inc. (Sarasota, FL) and used at $1 \mu \mathrm{g} / \mathrm{ml}$. CTLA4Ig and control fusion protein L6Ig (9) were generous gifts from P. Linsley (Bristol-Myers Squibb Pharmaceutical Research Institute, Seattle, WA). The following monoclonal antibodies were purchased from American Tissue Type Culture Collection (Rockville, MD): anti-LFA-1 alpha chain CD1 la (TS1/22; IgG1), anti-HLA-DR (L243JG1). Monoclonal antibodies 1C12D7 (anti-von-Willebrands factor, VWF; IgG1) and anti-CD19 (control IgG1) were gifts from D. Fox 
(University of Michigan). Fluorescein isothiocyanate-conjugated goat anti-mouse or goat anti-human second-step antibodies for FACS analysis were purchased from Beckton-Dickinson (Mountain View, CA).

Cells. Keratome biopsies (two to four slices each measuring $2 \times 5 \mathrm{~cm}$ ) of normal human skin were obtained after informed consent and approval of the University of Michigan Human Subjects Committee, and incubated in Dispase (Boehringer-Mannheim, Mannheim, Germany) at a final concentration of $1.2 \mathrm{U} / \mathrm{ml}$ in RPMI 1640 for $1 \mathrm{hr}$ at $37^{\circ} \mathrm{C}$. After the incubation period, epidermis and dermis could be easily separated. Each piece of tissue was separately rinsed several times in phosphate-buffered saline, cut into small pieces $(\sim 1-10 \mathrm{~mm})$, and placed in RPMI 1640 supplemented with 10\% FBS in 10-cm tissue culture plates (Corning Inc., Corning, NY). After 2 or 3 days, cells that migrated out of the respective tissue sections (epidermis and dermis) into the medium were spun down, resuspended in 1-2 ml fresh medium, and stained with trypan blue to assess viability. Migrating cells out of the epidermis are designated as Langerhans cells (LCs), and cells migrating out of dermis are designated as dermal dendritic cells. Further enrichment of dendritic cells was achieved through separation with a metrizamide gradient as described $(16,17)$. Briefly, cells were layered onto 3$\mathrm{ml}$ columns of hypertonic $14.5 \%$ metrizamide (Accurate Chemical \& Scientific Corp., Westbury, NY) and sedimented at $650 \mathrm{~g}$ for $10 \mathrm{~min}$ at room temperature. Low-density interphase cells were collected and washed in two successively less hypertonic washes (RPMI 1640 supplemented with $10 \%$ FBS and $40 \mathrm{mM} \mathrm{NaCl}$ for wash 1 and $25 \mathrm{mM}$ $\mathrm{NaCl}$ for wash 2) to return cells to isotonicity.

Human blood DCs were isolated using standard procedures involving multistep negative selection (16). Briefly, human PBMC were enriched from heparinized peripheral blood of healthy normal donors by density centrifugation over Ficoll-Hypaque (Pharmacia LKB, Piscataway, NJ). T lymphocytes were separated from PBMC by rosetting at $4{ }^{\circ} \mathrm{C}$ with neuraminidase-treated sheep red blood cells followed by FicollHypaque sedimentation. The $\mathrm{T}$ cell depleted erythrocyte-rosette negative fraction was cultured for $36 \mathrm{hr}$ at $37^{\circ} \mathrm{C}$ in $100-\mathrm{mm}$ dishes. Nonadherent cells were panned twice on bacteriologic dishes coated with human immunoglobulin to deplete FcR-bearing monocytes (17). Monocyte and $\mathrm{T}$ cell depleted fractions were further enriched using metrizamide columns (16). All DC populations were at least $60 \%$ pure as assessed by FACS analysis.

Plastic adherent monocytes were obtained by allowing the PBMC to adhere to plastic dishes for $2 \mathrm{hr}$ at $37^{\circ} \mathrm{C}$. After washing nonadherent cells, the attached cells were removed from the dish by scraping and resuspended in RPMI $+10 \%$ FBS.

Highly purified resting $T$ cells were obtained by vigorous negative selection with goat anti-mouse IgG-coated magnetic beads (Advanced Magnetic, Cambridge, MA) and a cocktail of murine antibodies directed against B cells, monocytes, NK cells, and activated $\mathrm{T}$ cells as previously described (18). T cells purified by this procedure were always more than $98 \% \mathrm{CD}^{+} / \mathrm{CD}^{+}$. No HLA-DR positive $\mathrm{T}$ cells were detected by FACS analysis.

Immunoperoxidase staining. Immunoperoxidase staining of cytospin preparations used a highly sensitive avidin-biotin technique (Vectastain, Vector Labs, Burlingame, CA) performed as previously described (13). For all experiments, appropriate isotype and second-step controls were included.

Proliferation assays. For SA and allogeneic reactions, various APCs were cocultured at the indicated concentrations with $5 \times 10^{4}$ purified $\mathrm{T}$ cells in 96-well round-bottom 
culture plates (Costar, Cambridge, MA) in $200 \mu$ of RPMI $1640+10 \%$ FBS at $37^{\circ} \mathrm{C}$ in $5 \% \mathrm{CO}_{2}$ humidified incubator. Cells were pulsed for the final $18 \mathrm{hr}$ of the incubation period with $1 \mu \mathrm{Ci} /$ well of $\left[{ }^{3} \mathrm{H}\right] \mathrm{TdR}$ (New England Nuclear, Boston, MA), and harvested onto glass microfiber filterstrips using a PHD cell harvester (Cambridge Technologies, Cambridge, MA), and placed in a liquid scintillation counter. Culture duration was 3 days for SEB-mediated $T$ cell stimulation and 6 days for alloantigen-stimulated cultures. Values are expressed as the mean cpm \pm SD of triplicate wells. In blocking experiments, $\mathrm{mAbs}$ or appropriate isotype controls were added to $\mathrm{T}$ cells at the indicated concentrations throughout the incubation period. At least four different experiments were carried out for each experimental protocol.
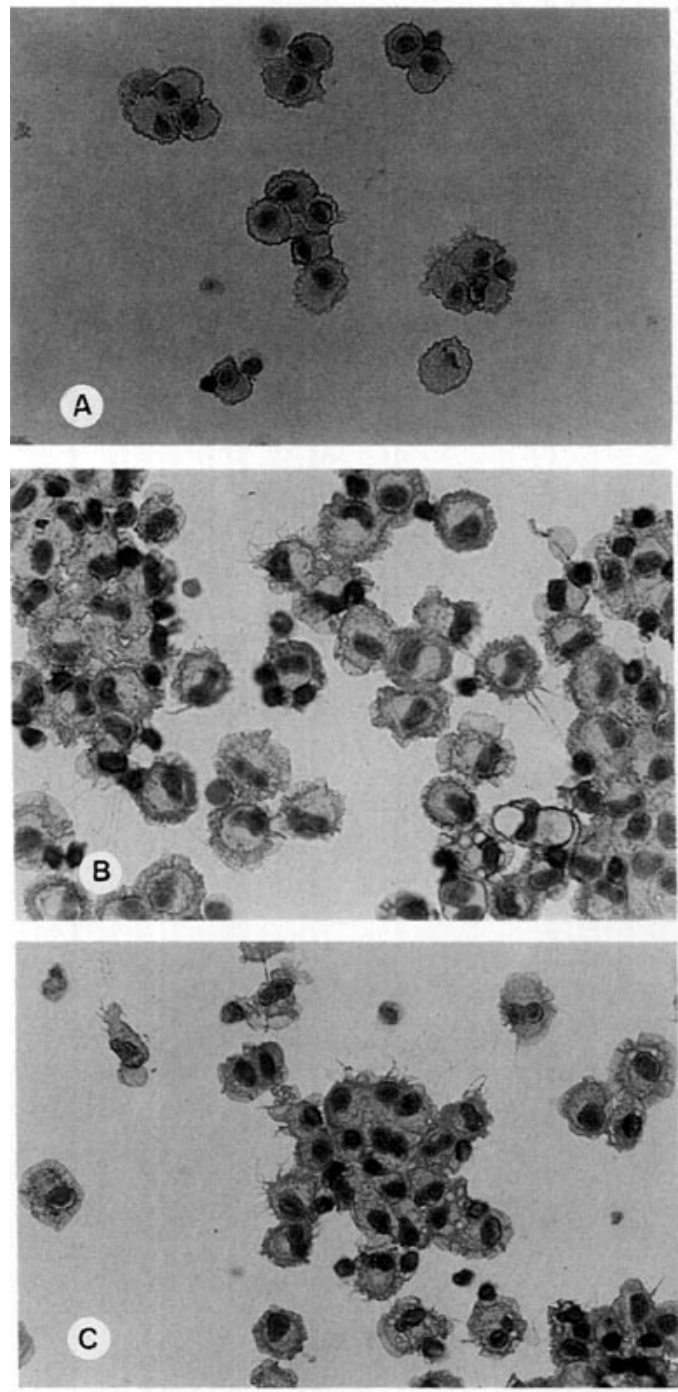

FiG. 1. HLA-DR expression on cytospin preparations of dendritic cells. (A) Epidermal Langerhans cells. (B) Blood dendritic cells. (C) Dermal dendritic cells. Note the strong staining (red immunoperoxidase reaction product) of dendritic cells. Magnification, $\times 180$. 


\section{RESULTS}

Since there have been conflicting reports regarding the involvement of the accessory molecule B7 in SA-mediated T cell activation using allogeneic cell lines as APCs, we explored its role in an autologous system using human resting $\mathrm{T}$ cells as responders and various types of nontransformed APCs. The autologous APC subsets utilized included: PBMC, plastic adherent monocytes, LCs, dermal DCs, blood DCs. We chose DCs from different anatomical sites as APCs for three reasons: (i) DCs are APCs which function in a sentinel role in vitro and in vivo for initiating primary immune responses (10); (ii) DCs are known to express high levels of MHC class II molecules that are required to present SA (19) and are more efficient in presenting SA than other APCs, like monocytes or B cells (15); (iii) DCs (especially from blood and skin) are likely to be amongst the initial type of APCs which encounter bacterial-derived SA.

By FACS analysis the large DCs could be clearly distinguished as a separate population from other nondendritic cell types by their high forward and side scatter properties (data not shown). When DCs were visualized by immunostaining of prepared cytospins, a homogenous population of large cells (compared to rare smaller contaminating $T$ cells) with numerous delicate membrane protrusions could be observed. Staining with antibody against HLA-DR revealed strong surface reactivity and demonstrated fully extended dendritic processes (Fig. 1). To confirm that our cultured cells express B7, we examined by flow cytometry highly enriched epidermal, dermal, and blood-derived DCs, as well as PBMC and plastic adherent monocytes. FACS analysis using CTLA4Ig demonstrated that all DC populations had strong cell surface reactivity for $\mathrm{B} 7$ (Fig. 2, peaks D, E, and F). Plastic adherent monocytes (Fig. 2, peak C) were B7 positive (albeit with less fluorescence intensity than DCs). In contrast,

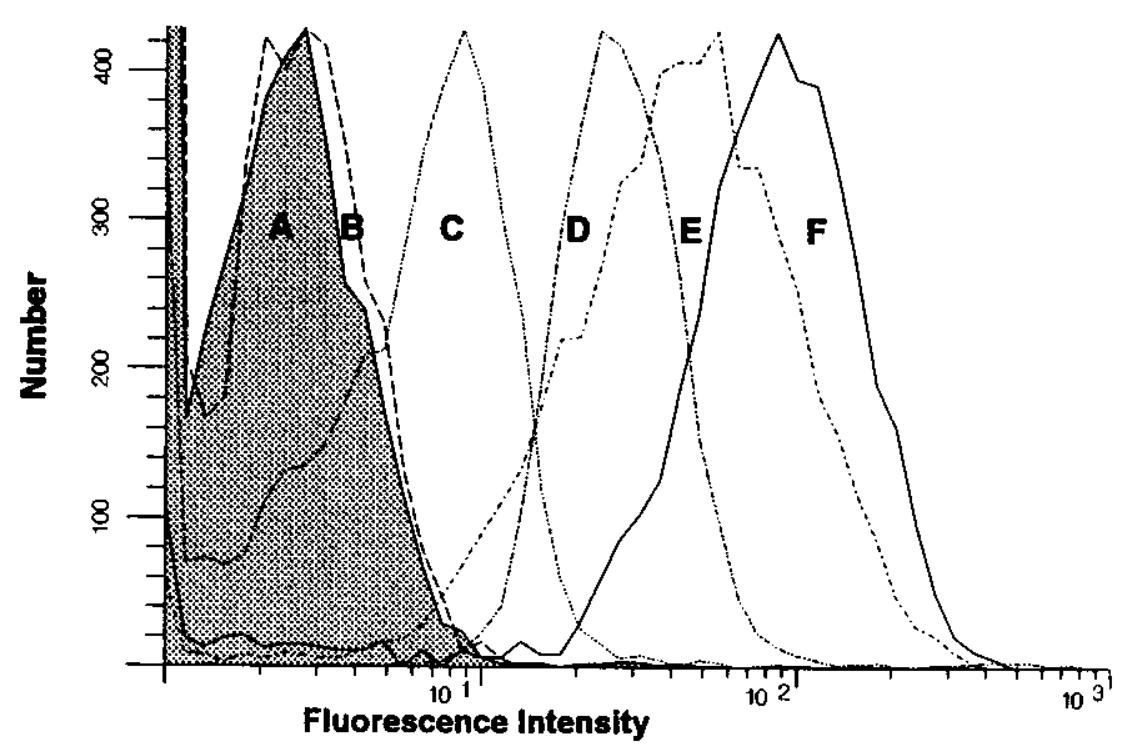

FIG. 2. B7 expression on mononuclear cells and dendritic cells. APCs were stained using CTLA4Ig and L6Ig, and analyzed by FACS. APC populations include A and B; Ficoll-Hypaque-derived PBMCs. (A) Isotype L6Ig control staining; (B-F) B7 staining of (C) plastic adherent monocytes, (D) dermal dendritic cells, (E) blood dendritic cells, (F) Langerhans cells. 
freshly isolated PBMC containing 20-30\% monocytes plus B cells (Fig. 2, peak B) were only slightly above the background level of L6Ig staining (Fig. 2, peak A).

To explore the potential capability of PBMC, adherent monocytes, blood DCs, dermal DCs, and LCs to function as APCs in a purely autologous system, SEB was added to resting peripheral blood $T$ cells. Verification that the $T$ cell isolation procedure effectively removed other functional blood-derived accessory cells was accomplished by adding PHA or SEB alone to the resting T cells. Figure 3 (left side) demonstrates that HLA-DR negative $T$ cells were devoid of accessory cells since only background levels $(<400 \mathrm{cpm})$ of proliferation are seen for either T cells alone, T cells plus SEB, or T cells plus PHA. While all of the isolated APCs express class II MHC (data not shown), and hence are capable of binding SEB (19), differences were noted in their relative ability to present $\mathrm{SEB}$. When $5 \times 10^{4} \mathrm{PBMCs}$ were exposed to $\mathrm{SEB}$, there was vigorous $T$ cell proliferation $(54,500 \pm 8300 \mathrm{cpm})$. In contrast to the mixed APC population present in PBMCs, when highly purified preparations of APCs were used, such as the DCs, only $5 \times 10^{2}$ cells per well were required for a similar level of stimulation. Figure 3 (right side) reveals that high levels of $T$ cell proliferation $(>40,000$ cpm) were observed using SEB for all three types of DCs. When $5 \times 10^{2}$ adherent monocytes were used, only slight $T$ cell proliferation occurred upon addition of SEB (Fig. 3). Using $5 \times 10^{3}$ adherent monocytes as APCs, a greater level of T cell proliferation with SEB was induced $(55,000 \mathrm{cpm})$.

When the same number of APCs were combined with allogeneic $T$ cells in the absence of SEB, a similar relative degree of $\mathrm{T}$ cell proliferation was observed (Fig. 4A) as noted above in the autologous system using SEB. Thus, all three types of DCs were more potent stimulators of allogeneic reactions compared to adherent monocytes or PBMCs.

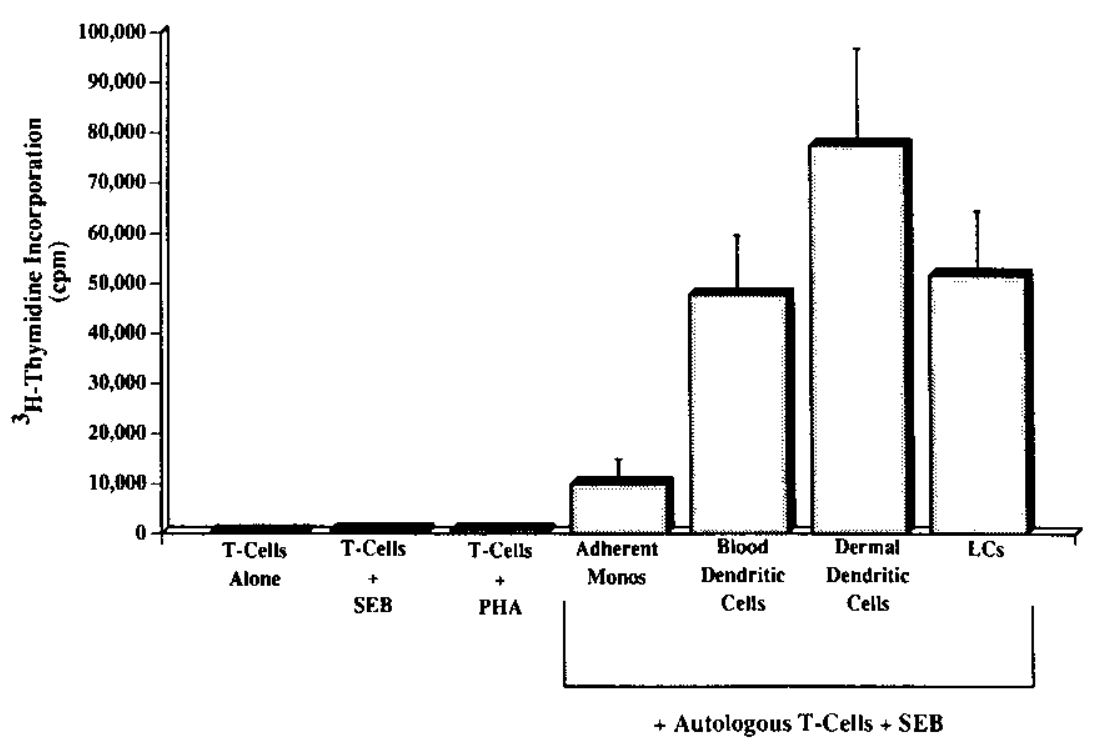

FIG. 3. The proliferative response of autologous, resting, peripheral T cells $\left(5 \times 10^{4}\right.$ cells/well $)$ to either medium alone, SEB alone, PHA alone, or with the indicated APCs $\left(5 \times 10^{2}\right.$ cells/well $)$ in the presence of SEB was determined as described under Materials and Methods. 

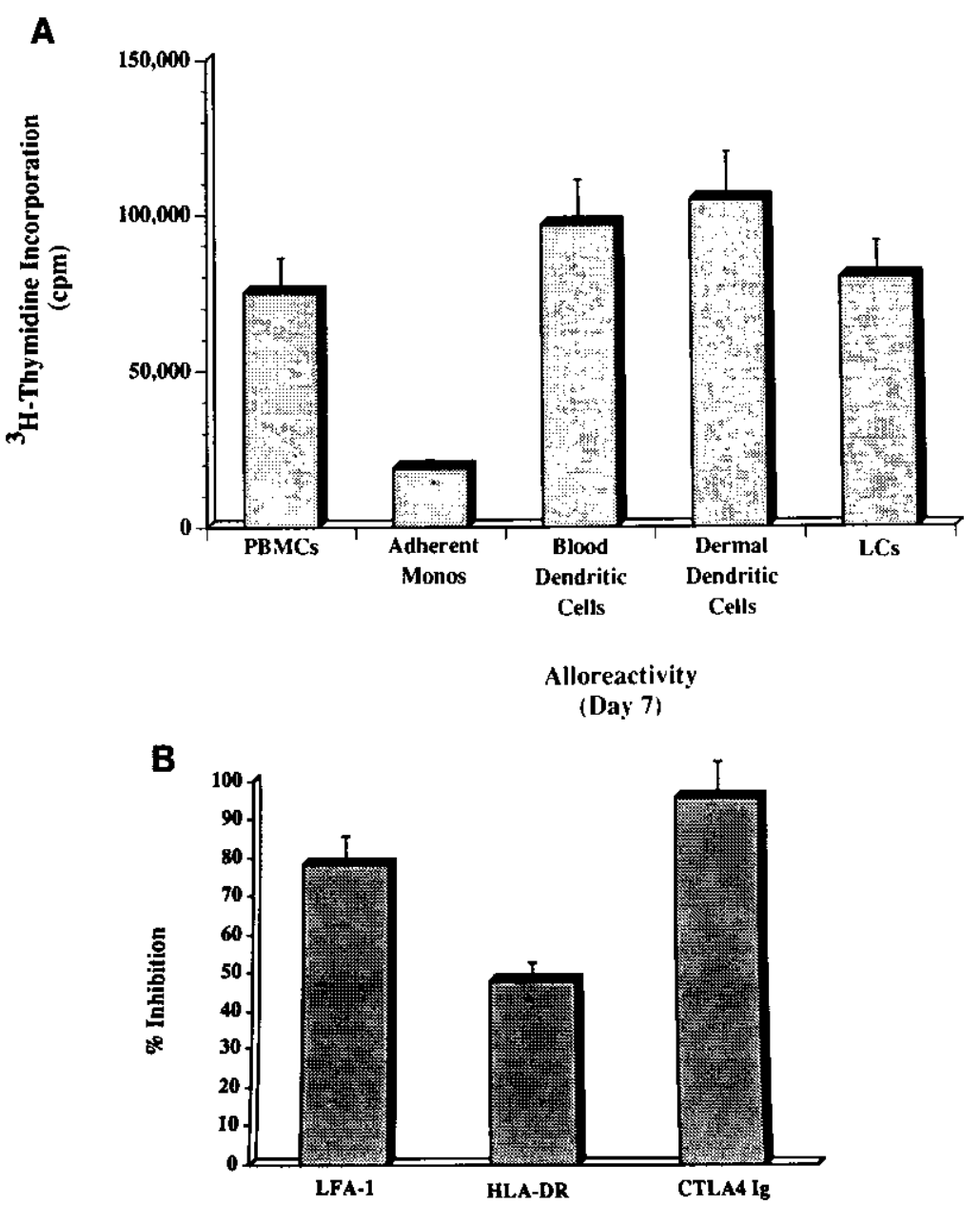

Fig. 4. (A) Stimulation of T cells by PBMC $\left(5 \times 10^{4} /\right.$ well $)$, or $5 \times 10^{2}$ cells $/$ well of the indicated allogeneic APCs. (B) Inhibition of T cell responses against allogeneic dermal dendritic cells using antibodies $(10 \mu \mathrm{g} /$ ml) against LFA-1, HLA-DR, and CTLA4Ig.

We next investigated the role of B7 and other accessory cell surface molecules involved in APC:T cell interactions. Proliferation of resting T cells to allogeneic dermal dendritic cells ( 500 cells/well) was blocked by antibodies $(10 \mu \mathrm{g} / \mathrm{ml})$ against LFA-1 (78\%), HLA-DR (48\%), and by CTLA4Ig (95\%), but not by control (anti-CD19, antiVWF) antibodies or L6Ig (Fig. 4B). With dermal DCs as the APC, SEB as mitogen, and autologous resting $T$ cells as responders, a dose-dependent inhibition could be observed with antibodies against LFA-1, HLA-DR, and by CTLA4Ig, but not by control antibodies (Fig. 5). Using CTLA4Ig at $10 \mu \mathrm{g} / \mathrm{ml}$, the SEB-mediated T cell proliferative response with autologous plastic adherent monocytes, blood DCs, dermal DCs, and LCs (used at 500 cells/well) was also inhibited between 55 and $85 \%$ (Fig. $6 \mathrm{~A}$ ). In contrast, using PBMC (at $5 \times 10^{4}$ cells/well), the SEB-induced T cell response was not significantly inhibited by CTLA4Ig. Using antibody against LFA-1, all APCs (including PBMC) were inhibited by $80 \%$ in the SEB-driven $\mathrm{T}$ cell proliferative response (Fig. 6B). 


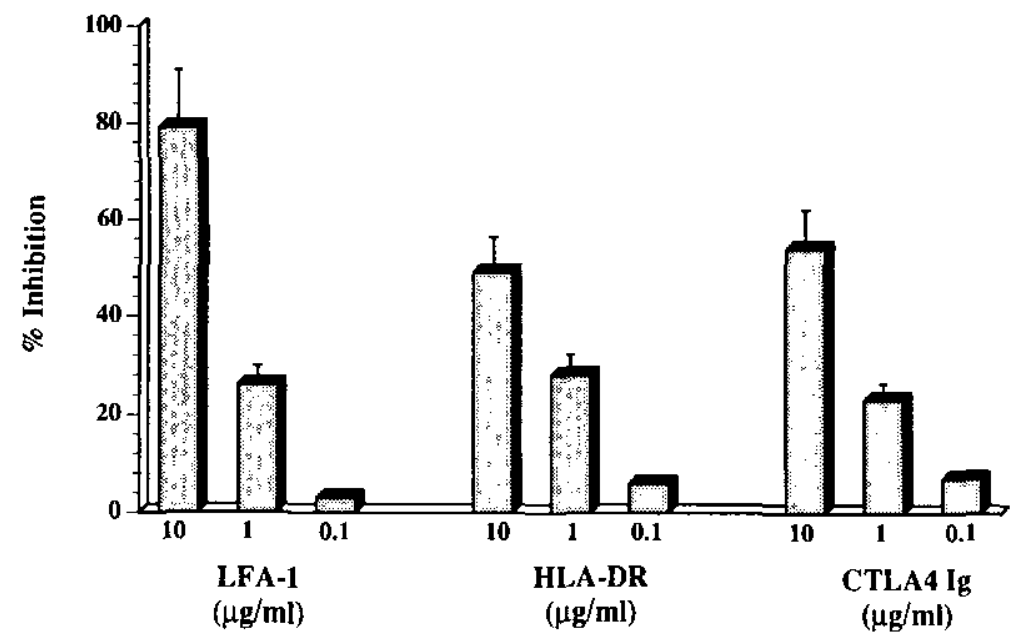

FIG. 5. Dose-dependent inhibition of the proliferative response of autologous resting $T$ cells to dermal dendritic cells and SEB using mAbs against LFA-1, HLA-DR, or CTLA4Ig. No inhibition was observed using control mAbs against CD19, VWF, or L6Ig.

\section{DISCUSSION}

These results indicate that there are at least two distinct costimulatory pathways utilized by APCs for SEB-induced T cell proliferation. The first is clearly B7-dependent and is functionally operative when the class II MHC positive APCs express high levels of B7, such as is seen with DCs. Consistent with these results is the recent report that transfection of human $B$ 7 into murine $L$ cells (producing high surface levels of expression) augmented the proliferative response of T cells to SEB (20). The second pathway is B7-independent and is used by APCs expressing low levels of B7, such as the APCs present in freshly isolated mononuclear cells from peripheral blood. Other class II MHC positive cells capable of providing B7-independent costimulation for SA include gamma interferon-treated human umbilical vein endothelial cells (8) and keratinocytes (18). For endothelial cells only a low level of B7 is expressed (similar to PBMCs), where keratinocytes express no B7 (13). The fact that B7 blockade by CTLA4Ig reduced the autologous SEB-mediated T cell proliferation supported by DCs by $55-85 \%$, but did not eliminate it completely, suggests that DCs, even though they express functional B7, may also utilize other costimulatory or adhesion receptor-ligand interactions including LFA-1. This result is in contrast to what is observed with alloantigen, where proliferation is more completely blocked by CTLA4Ig.

In this regard, it is of interest that $\mathrm{B} 7$-dependent costimulation for alloantigen is observed with PBMCs expressing only low levels of B7. Furthermore, IFN- $\gamma$-treated keratinocytes that express no B7 fail to stimulate an allogeneic response (18). Thus, even low levels of $B 7$ expression may be critically important for an allogeneic response. Whether transfection of B7 into keratinocytes will produce cells which can stimulate an allogeneic $T$ cell proliferative response remains to be determined. These results indicate a hierarchy with respect to the functional significance of B7 expressed by APCs. For autologous APCs, low levels of B7 do not significantly contribute to SEBmediated reactions as observed for PBMCs, but on plastic adherent monocytes and three different types of DCs which have greater B7 expression, the SEB-mediated 

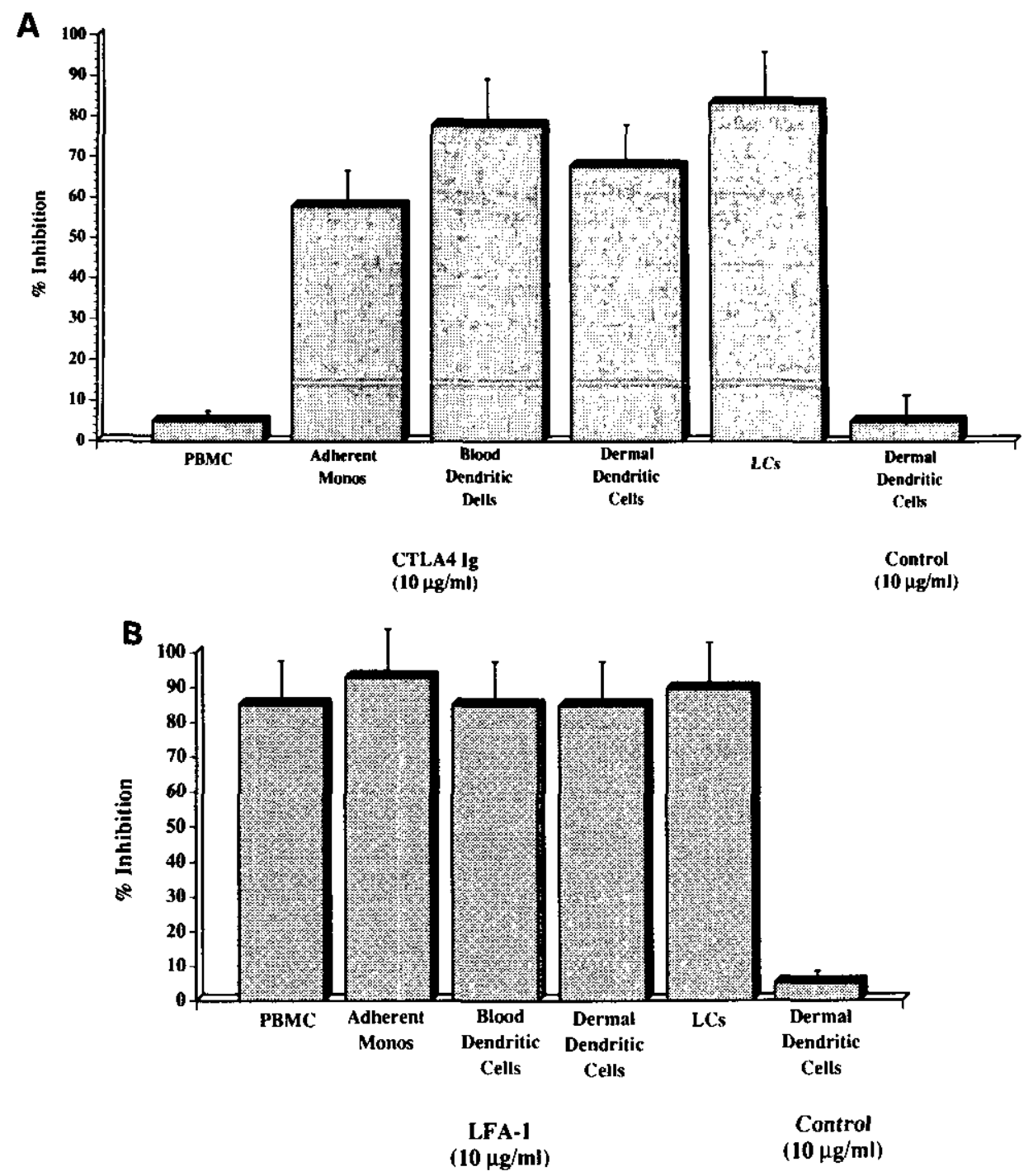

FIG. 6. (A) CTLA4Ig inhibits SEB-mediated proliferation of autologous resting $T$ cells presented by adherent monocytes and dendritic cells, but not PBMCs. No inhibition was observed using L6Ig. (B) Antibody against LFA-1 inhibits SEB-mediated proliferation of autologous resting $T$ cells for all APCs. No inhibition was observed using the control mAb, anti-CD19.

reaction clearly has a B7-dependent component. In contrast for allogeneic reactions, even APC populations with low levels of $B 7$ can stimulate $T$ cell response that are strongly inhibited by CTLA4Ig. Thus, it appears that the ability of T cells to utilize the B7-dependent pathway is a function of the qualitative nature of the primary stimulus delivered to the $\mathrm{T}$ cell (SA vs alloantigen) and the quantitative level of $\mathrm{B} 7$ expression by the APC.

These in vitro results suggest that the observed in vivo expression of $\mathbf{B} 7$ on DCs in normal and diseased skin, such as psoriasis $(13,14)$, could have functional significance 
because psoriasis is triggered by bacterial infections. Moreover, bacterial-derived SA has been detected in psoriasis, and antibodies raised against bacterial antigens highlight DCs in tissue sections of lesional skin $(21,22)$. Further studies on the importance of dendritic cells in cutaneous disease triggered by bacterial infection, particularly focusing on B7, are indicated to gain new insight into the pathophysiology of the initiation and amplification of the $\mathrm{T}$ cell-mediated immune response occurring in skin.

\section{ACKNOWLEDGMENTS}

The authors thank X. G. Zheng and R. Mitra for assistance in the laboratory, and Dr. James W. Young (Rockefeller University) and Dr. Nikolaus Romani (University of Innsbruck) for helpful suggestions regarding isolation of dendritic cells.

\section{REFERENCES}

1. Schwartz, R. H., Science 248, $1349,1990$.

2. June, C. H., Ledbetter, J. A., Linsley, P. S., and Thompson, C. B., Immunol. Today 11, $211,1990$.

3. Linsley, P. S., Clark, E. A., and Ledbetter, J. A., Proc. Natl. Acad. Sci. USA 87, 5031, 1990.

4. Linsley, P. S., Brady, W., Grosmaire, L., Aruffo, A., Damle, N. K., and Ledbetter, J. A., J. Exp. Med. $173,721,1991$.

5. Gimmi, C. D., Freeman, G. J., Gribber, J. G., Sugita, K., Freedman, A. S., Morimoto, C., and Nadler, L. M., Proc. Nat. Acad. Sci. USA 88, 6575, 1991.

6. Koulova, L., Clark, E. A., Shu, G., and Dupont, B., J. Exp. Med. 173, 759, 1991.

7. Fraser, J. D., Newton, M. E., and Weiss, A., J. Exp. Med. 175, 1131, 1992.

8. Damle, N. K., Klussman, K., Leytze, G., and Linsley, P. S., J. Immunol. 150, 726, 1993.

9. Linsley, P. S., Brady, W., Urnes, M., Grosmaire, L. S., Damle, N. K., and Ledbetter, J. A., J. Exp. Med. 174, 561, 1991.

10. Steinman, R. M., Rev. Immunol. 9, 271, 1991.

11. Young, J. W., Koulova, L., Soergel, S. A., Clark, E. A., Steinman, R. M., and Dupont, B., J. Clin. Invest. 90, 229, 1992.

12. Larsen, C. P., Ritchie, S. C., Pearson, T. C., Linsley, P. S., and Lowry, R. P., J. Exp. Med. 176, 1215, 1992.

13. Nickoloff, B. J., Mitra, R. S., Lee, K., Turka, L. A., Green, J., Thompson, C., and Shimizu, Y., Am. J. Pathol. 142, 1029, 1993.

14. Symington, F. W., Brandy, W., and Linsley, P. S., J. Immunol. 150, 1286, 1993.

15. Bhardwaj, N., Friedman, S. M., Cole, B. C., and Nisanian, A. J., J. Exp. Med. 175, 267, 1992.

16. Freudenthal, P. S., and Steinman, R. M., Proc. Nat. Acad. Sci. USA 87, 7698, 1990.

17. Young, J. W., and Steinman, R. M. Cell Immunol. 111, 167, 1988.

18. Nickoloff, B. J., Mitra, R. S., Green, J., Zheng, X. G., Shimizu, Y., Thompson, C., and Turka, L. A., J. Immunol. 150, 2148, 1993.

19. Herman, A., Croteau, G., Sekaly, R-P., Kappler, J., and Marrack, P., J. Exp. Med. 172, 709, 1992.

20. Goldbach-Mansky, R., King, P. D., Taylor, A. P., and Dupont, B., B. Int. Immunol. 4, 1351, 1992.

21. Leung, D. Y. M., Walsh, P., Giorno, R., and Norris, D. A., J. Invest. Dermatol. 100, 225, 1993.

22. McFadden, J., Valdimarsson, H., and Fry, L., Br. J. Dermatol. 125, 443, 1991. 